\title{
PHYTOCHEMICAL SCREENING AND ANTIMICROBIAL ACTIVITY OF ROOTS OF MURRAYA KOENIGII (LINN.) SPRENG. (RUTACEAE)
}

\author{
Manisha Vats*, Harneet Singh, Satish Sardana \\ Department of Pharmacognosy, Hindu College of Pharmacy, Sonipat 131001, Haryana, India.
}

Submitted: July 22, 2009; Approved: May 23, 2011.

\begin{abstract}
Murraya koenigii, family Rutaceae, commonly known as Curry leaf plant is a highly valued plant for its medicinal value and characteristic aroma. The plant is a rich source of carbazole alkaloids. The petroleum ether, chloroform, ethyl acetate and ethanol extracts of roots of the plant were screened for phytochemical properties and antimicrobial activity for Staphylococcus aureus, Micrococcus luteus, Bacillus subtilis, Escherichia coli, Pseudomonas aeruginosa, Candida albicans and Aspergillus niger. Phytochemical screening showed the presence of carbohydrates, alkaloids, steroids and flavonoids in the root extracts of the plant. The study shows that all the extracts possess remarkable antibacterial activity. Additionally, petroleum ether and chloroform extracts also had antifungal activity.
\end{abstract}

Key words: Murraya koenigii, Rutaceae, phytochemical screening, antimicrobial activity.

\section{INTRODUCTION}

Murraya koenigii (Linn,) Spreng. (Family-Rutaceae) commonly called Curry leaves in trade, occurs throughout India up to an altitude of 1500 metres (1). The leaves of the plant are used as a flavoring agent.

Medicinally, these leaves found use in diarrhea, dysentery and to prevent vomiting. The Leaves and fruits are also a source of an essential oil which finds use as a fixative for heavy type of soap perfume. Leaves, root and bark are tonic, stomachic and carminative. Juice of roots provides relief from renal pain (8). Previous phytochemical investigations on this plant revealed the presence of carbazole alkaloids $(3,6,10,12,13,14,15,16)$ and coumarins (2). The present study is aimed at preliminary phytochemical screening of the root extracts of Murraya koenigii and evaluation of the same for potential antimicrobial activity.

\section{MATERIALS}

Petroleum ether, Chloroform, Ethyl acetate, Ethanol (95\%) and Dimethyl Sulphoxide (DMSO) were purchased from RFCL, India. Nutrient agar and Sabouraud dextrose agar media were obtained from Himedia, India. The

\footnotetext{
*Corresponding Author. Mailing address: Department of Pharmacognosy, Hindu College of Pharmacy, Sonipat 131001, Haryana, India.; Tel.: -09416918840, E-mail: ms.vats@yahoo.com
} 
microorganisms were availed from Institute of Microbial Technology, Chandigarh, - India (Invoice No. MTCC/08/10/5396). Ciprofloxacin and Fluconazole were a generous gift from Ranbaxy Laboratories Ltd., India.

microorganisms were availed from Institute of Microbial Technology, Chandigarh, - India (Invoice No. MTCC/08/10/5396). Ciprofloxacin and Fluconazole were a generous gift from Ranbaxy Laboratories Ltd., India.

\section{METHODS}

\section{Plant Collection and identification}

The roots of Murraya koenigii were collected in October 2008, from healthy plants in Ambala, India and shade dried. The plant material was identified by Raw Materials Herbarium and Museum, NISCAIR, India (NISCAIR/RHMD/ Consult/- 2008-09/1079/110).

\section{Extraction and phytochemical screening}

The collected dried roots were coarsely powdered and extracted sequentially with petroleum ether $\left(60-80^{\circ} \mathrm{C}\right)$, chloroform, ethyl acetate and ethanol (95\%) using Soxhlet apparatus. The extracts were screened for the presence of different phytoconstituents like saponins (Frothing test), tannins (Ferric chloride test and Lead acetate test) alkaloids, (Dragendroff's test, Meyer's test, Hager's test,and Wagner's test) glycosides ( Brontrager's test for anthraquinone glycosides and Killer-Killani's test for cardiac glycosides), steroids (Salkowski test and Libarman-Burchard's test) and flavonoids (Shinoda's test, Ferric chloride test, and Pew test) $(5,13)$.

\section{Microorganisms}

The test organisms (Staphylococcus aureus MTCC 737, Micrococcus luteus MTCC 106, Bacillus subtilis MTCC 441, Escherichia coli MTCC 443, Pseudomonas aeruginosa MTCC 1688, Candida albicans MTCC 3017 and Aspergillus niger MTCC 1344) were sub cultured onto nutrient agar in order to determine their viability. The identity of each test organism was confirmed using standard cultural, morphological and biochemical techniques (4). Stock cultures were maintained on nutrient agar slants at $4^{\circ} \mathrm{C}$ and sub cultured in nutrient broth at $37^{\circ} \mathrm{C}$ prior to each antimicrobial test.

\section{Evaluation of antimicrobial activity}

All the experimentation was done in aseptic area under laminar air-flow cabinet. Modified agar diffusion method (7) was adopted for this study. Molten agar medium $(25 \mathrm{ml})$ was taken in a sterile petridish and broth cultures of the test isolate $(0.1 \mathrm{ml})$ containing $1.0 \times 10^{5} \mathrm{CFU} / \mathrm{ml}$ of organism were added. The contents were thoroughly mixed and allowed to solidify. The extracts were dissolved in DMSO and used in 10, 20, 40 and $50 \mathrm{mg} / \mathrm{ml}$ concentrations. Ciprofloxacin and Fluconazole $(10 \mu \mathrm{g} / \mathrm{ml})$ were used as standard antibacterial and antifungal agents. Wells were bored in the plates, using a standard sterile cork borer of $8 \mathrm{~mm}$ diameter and equal volumes of the plant extracts $(1000 \mu \mathrm{l})$ was transferred into the well with using micropipette. The plates were kept for $1 \mathrm{hr}$ for pre-diffusion and incubated at $37^{\circ} \mathrm{C} / 24 \mathrm{hr}$ (plates containing bacterial cultures), $25^{\circ} \mathrm{C} / 3$ days (plates containing Candida albicans culture) and $25^{\circ} \mathrm{C} / 7$ days (for plates containing Aspergillus niger culture). At the end of incubation, zone of inhibition was measured in all the plates.

\section{RESULTS AND DISCUSSION}

The extractive values for petroleum ether, chloroform, ethyl acetate and ethanol extracts was found to be $4.03 \%$, $1.31 \%, 0.59 \%$ and $9.4 \%$ respectively. The results of the phytochemical screening (Table 1) showed the presence of carbohydrates in all the extracts except chloroform extract and chloroform extract showed the presence of alkaloids. The flavonoids and sterols were found to present in ethyl acetate and ethanol extracts. Petroleum ether and chloroform extracts 
exhibited prominent antibacterial and antifungal activity (Table 3). The chloroform extract is showing good inhibitory properties for A. niger $>P$. aeruginosa $>C$. albicans (Graph 1). The MIC values of the extract against tested microorganisms are shown in Table 2. The results of the tests for MIC study revealed that the MIC for Bacillus subtilis, Pseudomonas aeruginosa and Escherichia coli were found to be less than that Staphylococcus aureus and Micrococcus luteus.

Table 1. Phytochemical screening of extracts of root of Murraya koenigii

\begin{tabular}{lcccc}
\hline Test & $\begin{array}{l}\text { Petroleum } \\
\text { Ether }\end{array}$ & Chloroform & $\begin{array}{l}\text { Ethyl } \\
\text { Acetate }\end{array}$ & Ethanol \\
\hline Alkaloids & - & + & - & - \\
Carbohydrates & + & - & + & + \\
Glycosides & - & - & - & - \\
Sterols & + & - & + & + \\
Saponins & - & - & - & - \\
Tannins & - & - & - & - \\
Proteins & - & - & - & - \\
Amino acids & - & - & - & + \\
Flavonoids & - & - & + & + \\
Starch & - & - & - & - \\
\hline Present $(+)$, Absent (-) & & & &
\end{tabular}

Table 2. MIC Study for extracts of root of Murraya koenigii

\begin{tabular}{ccccccc}
\hline Microorganism & Petroleum Ether & Chloroform & Ethyl Acetate & Ethanol & Cipro & Fluco \\
\cline { 2 - 6 } & \multicolumn{5}{c}{ MIC $(\boldsymbol{\mu g} / \mathbf{m l})$} \\
\hline S. aureus & 1.25 & 0.625 & 0.625 & 1.25 & 0.625 & - \\
B. subtilis & 0.625 & 0.625 & 0.625 & 1.25 & 0.625 & - \\
M. luteus & 1.25 & 1.25 & 1.25 & 1.25 & 0.625 & - \\
E. coli & 0.625 & 1.25 & 0.625 & 1.25 & 0.312 & - \\
P. aeruginosa & 0.625 & 0.625 & 0.625 & 1.25 & 0.312 & - \\
A. niger & 1.25 & 0.625 & - & - & - & 0.625 \\
C. albicans & 2.50 & 1.25 & - & - & - & 1.25 \\
\hline Cipro-ciprofloxacin, Fluco-fluconazo & & & & &
\end{tabular}

Cipro-ciprofloxacin, Fluco-fluconazole

Table 3. Antimicrobial activity (zone of inhibition) of extracts of root of Murraya koenigii

\begin{tabular}{|c|c|c|c|c|c|c|c|c|c|c|c|c|c|c|c|c|c|c|}
\hline \multirow{2}{*}{$\begin{array}{l}\text { Extracts } \\
\text { Conc. }(\mathrm{mg} / \mathrm{ml})\end{array}$} & \multicolumn{4}{|c|}{ Petroleum Ether } & \multicolumn{4}{|c|}{ Chloroform } & \multicolumn{4}{|c|}{ Ethyl Acetate } & \multicolumn{4}{|c|}{ Ethanol } & \multirow{2}{*}{$\begin{array}{c}\text { Cipro } \\
10(\mu \mathrm{g} / \mathrm{ml})\end{array}$} & \multirow{2}{*}{$\begin{array}{c}\text { Fluco } \\
10(\mu \mathrm{g} / \mathrm{ml})\end{array}$} \\
\hline & 10 & 20 & 40 & 50 & 10 & 20 & 40 & 50 & 10 & 20 & 40 & 50 & 10 & 20 & 40 & 50 & & \\
\hline & \multicolumn{18}{|c|}{ Zone of Inhibition } \\
\hline S. aureus & - & - & - & 9 & 12 & 13 & 14 & 15 & 5 & 6 & 7 & 8 & 5 & 9 & 10 & 12 & 15 & NA \\
\hline B. subtilis & 14 & 16 & 17 & 17 & 12 & 13 & 14 & 16 & 8 & 10 & 16 & 17 & 6 & 9 & 12 & 14 & 23 & NA \\
\hline M. luteus & - & 4 & 7 & 12 & - & 3 & 7 & 11 & - & 5 & 8 & 12 & - & - & 5 & 9 & 21 & NA \\
\hline P. aeruginosa & 22 & 25 & 26 & 26 & 25 & 26 & 28 & 29 & 7 & 17 & 20 & 22 & 6 & 16 & 17 & 20 & 34 & NA \\
\hline E. coli & 8 & 13 & 18 & 19 & - & - & 4 & 8 & 4 & 7 & 10 & 12 & - & 3 & 5 & 10 & 31 & NA \\
\hline C. albicans & 9 & 12 & 16 & 17 & 14 & 16 & 21 & 22 & - & - & - & - & - & - & - & - & - & 23 \\
\hline A. niger & 9 & 10 & 11 & 12 & 9 & 10 & 12 & 15 & - & - & - & - & - & - & - & - & - & 19 \\
\hline
\end{tabular}

Cipro-ciprofloxacin, Fluco-fluconazole, NA-not applicable 


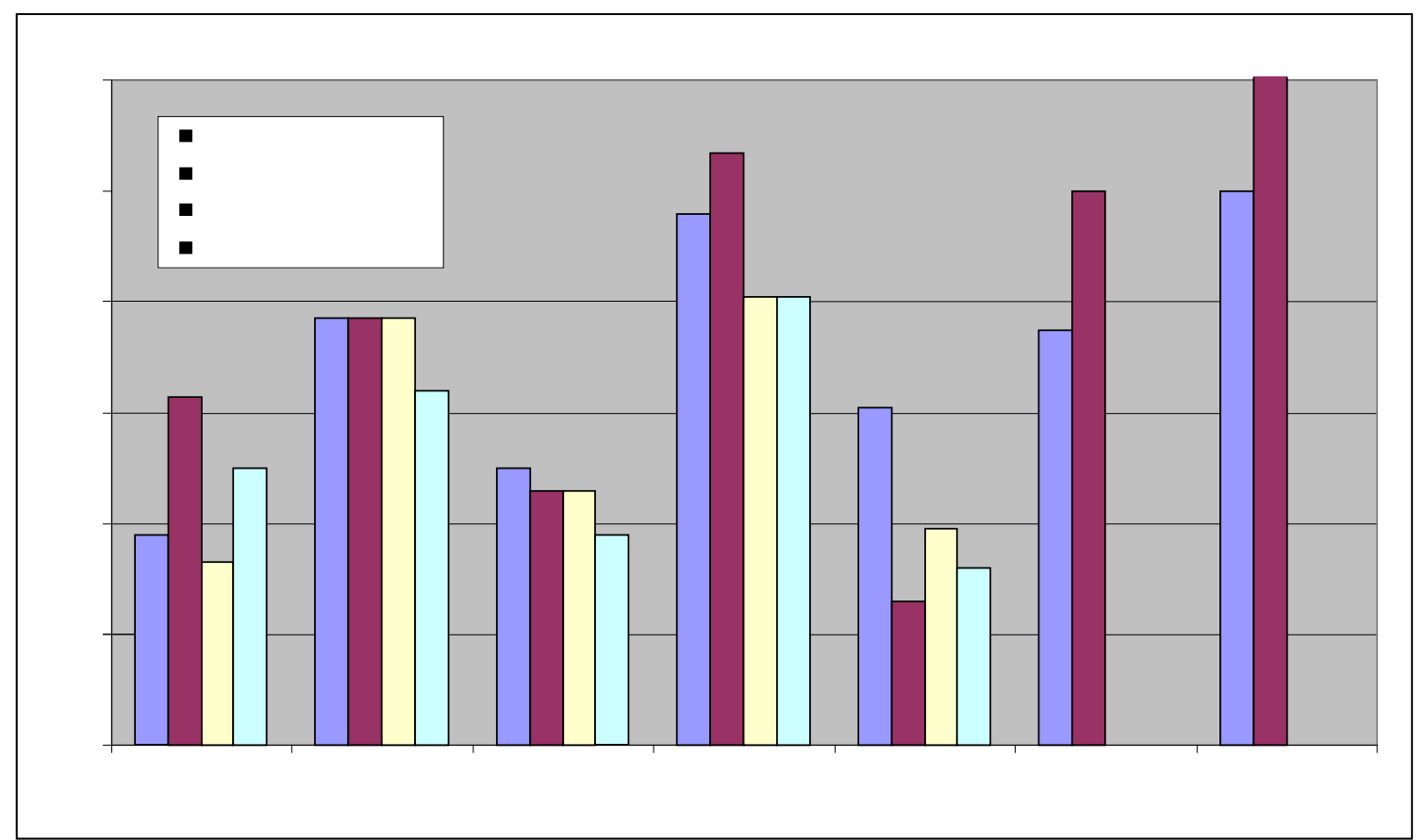

Graph 1. Comparision of antimicrobial activity of various extracts of root of Murraya koenigii

\section{CONCLUSION}

All the extracts of Murraya koenigii roots have antimicrobial property. As expected, the zone of inhibition (antimicrobial activity) is directly proportional to the extract concentration used. The chloroform extract is showing good inhibitory properties for $A$. niger $>$ P.aeruginosa $>C$. albicans and even at low concentrations. The Petroleum ether is inhibitory against $A$. niger $>$ P.aeruginosa. The data shows $E$. coli to be the most resistant microorganism of all microbes and a still higher concentration is required. Also, ethyl acetate and ethanolic extracts showed antibacterial activity but lacks any antifungal activity. These results shows that the root extract (chloroform, Petroleum ether) can be used to formulate antimicrobial compositions. However, further investigation with purified fractions is required to predict the exact mechanism of action.

\section{REFERENCES}

1. Anonymous. (1962). Wealth of India. A Dictionary of Indian
Raw Materials and Industrial Products. Vol. VII. New Delhi, Publications and Information Directorate, CSIR, New Delhi.

2. Adebajo, A.C.; Reisch, J. (2000). Minor furocoumarins of Murraya koenigii. Fitoterapia. 71, 334-337.

3. Bhattacharya, L.; Roy, S.K.; Chakraborty, D.P. (1982). Structures of the carbazole alkaloid isomurrayazoline from Murraya koenigii. Phytochemistry. 21, 2432-2433.

4. Cowan, M.; Steel, L. (1965). Preparation of the test organisms. Niger. J. Microbiol. 22, 56-60.

5. Harborne, J.B. (1973). Phytochemical Methods. Chapman and Hall Limited, London.

6. Ito, C.; Thoyama, Y.; Omura, M.; Kajiura, I.; Furukawa, H. (1993). Alkaloidal constituents of Murraya koenigii - isolation and structural elucidation of novel binary carbazolequinones and carbazole alkaloids. Chem. Pharm. Bull. 42, 2096-2100.

7. Iwaki, K.; Koya-Miyata, S.; Kohno, K.; Ushio, S.; Fukuda, S. (2006). Antimicrobial activity of Polygonum tinctorium Lour. extract against oral pathogenic bacteria. Nat. Med. 53, 72-79.

8. Kirtikar, K.R.; Basu, B.D. (1993). Indian Medicinal Plants. Lalit Mohan Basu Publishing, Allahabad, India.

9. Khan, A.; Rahman, M.; Islam, S. (2007). Antibacterial, antifungal and cytotoxic activities of tuberous roots of Amorphophallus campanulatus. Turk. J. Biol. 31, 167-172.

10. Nutan, M.T.H.; Hasan, C.M.; Rashid, M.A. (1999). Bismurrayafoline E: a new dimeric carbazole alkaloid from Murraya koenigii. Fitoterapia 
70, 130-133.

11. Osadebe, P.O.; Ukwueze, S.E. (2004). A comparative study of the phytochemical and antimicrobial properties of the Eastern Nigerian species of African Mistle foe (Loranthus nucranthus) sourced from different host trees. J. Biol. Res. Biotechnol. 2(1), 18-23.

12. Ramsewak, R.S.; Nair, M.G.; Strasburg, G.M.; Dewitt, D.L.; Nitiss, J.L. (1999). Biologically active carbazole alkaloids from Murraya koenigii. . Agri. Food Chem. 47, 444-447.

13. Rao, R.A.V.; Rhide, K.S.; Mujumdar, R.B. (1980). Mahanimbinol from Murraya koenigii. Chem. Ind. 17, 697-698.
14. Reisch, J.; Adebajo, A.C.; Kumar, V.; Aladesanmi, A.J. (1994). Two carbazole alkaloids from Murraya koenigii. Phytochemistry 36, 10731076.

15. Saha, C.; Chowdhury, B.K. (1998). Carbazoquinones from Murraya koenigii. Phytochemistry 48, 363-366.

16. Tachibana, Y.; Kikuzaki, H.; Lajis, N.H.; Nakatani, N. (2001). Antioxidative activity of carbazoles from Murraya koenigii. J. Agr. Food. Chem. 49, 5589-5594.

17. Trease, G.E.; Evans, W.C. (1989). Pharmacognosy (13th edn). English Language Book Society, Bailliere Tindall, Britain. 